\title{
Using data to explore trends in bridge performance
}

J. Bennetts MA (Cantab), MSc (Sur), GMICE

Department of Civil Engineering, University of Bristol, Bristol, UK;

Civil, Bridge and Ground Engineering, WSP, Bristol, UK (corresponding

author: john.bennetts@wsp.com)

G. T. Webb MEng, MA, PhD (Cantab). GMICE

Civil, Bridge and Ground Engineering, WSP, London, UK

\author{
P. J. Vardanega BE, MEngSc (QldUT), PhD (Cantab), GMICE, \\ MASCE, MIEAust, FHEA \\ Department of Civil Engineering, University of Bristol, Bristol, UK \\ (Orcid:0000-0001-7177-7851) \\ S. R. Denton MA, PhD (Cantab), CEng, FREng, FICE, FIStructE \\ Civil, Bridge and Ground Engineering, WSP, Bristol, UK \\ N. Loudon CEng, MICE, MCIHT \\ Safety, Engineering and Standards, Highways England, Bedford, UK
}

Asset management organisations collect large quantities of data on the inventory, condition and maintenance of their bridge structures. A key objective in the collection of these asset data is that these can be processed into useful information that can inform best practice for the design of new structures and the management of existing stocks. As a leading bridge asset owner, Highways England, UK, is applying insights from mining of its asset data to contribute to continual improvement in the management of structures and its understanding of their performance. This paper presents the application of modern data science tools and optimal decision tree learning to Highways England's asset information database comprising bridge inventory, inspection records and historic and current defects for its stock of thousands of bridges. Trends are observed in the factors affecting the current condition of bridges and their rate of deterioration. Optimal decision trees are used to identify the most influential factors in the performance of bridge structures and present complex multifactor trends in a format readily digested by managers and decision makers, to inform standards and policy.

\section{Notation}

$\mathrm{BCI}_{\text {ave }} \quad$ average bridge condition indicators

$\mathrm{BCI}_{\text {crit }} \quad$ critical bridge condition indicators

$\mathrm{ECI}_{\text {ave }} \quad$ average element condition indicator

$H \quad$ Shannon information entropy

$K \quad$ constant of proportionality

$P_{1}, P_{2}, \ldots, P_{n} \quad$ event probabilities

\section{Introduction}

Highways England is responsible for the operation, management and maintenance of England's Strategic Road Network, comprising approximately 21900 miles $\left(3.52 \times 10^{4} \mathrm{~km}\right)$ of road with 18500 built structures and carrying more than 85 billion journey miles $\left(1.37 \times 10^{11} \mathrm{~km}\right)$ every year (Highways England, 2014: pp. 15, 12). As with all bridge-owning organisations, it collects and stores large volumes of data regarding its assets' inventory, condition and maintenance histories. Developing useful information from this data is key to understanding the performance of these assets and providing feedback to inform and improve best practice and standards for bridge design and operation (UK Roads Liaison Group, 2016).

However, the tools and techniques typically used by practitioners for the analysis and presentation of data are poorly suited to the large volumes of data stored and limited in their capabilities. To address these issues, a structured research programme was developed by the authors to provide the evidence and analysis required to allow Highways England to understand factors influencing the condition of its bridge stock better. The rich asset information and intelligence developed in this work will enable Highways England to reduce, better target and better justify its expense on structures maintenance, thus enhancing the value derived from investments made at all stages of a structure's life cycle and the structures management systems used to support decision-making. The data used in this study are in the form of visual inspection records, which are the most commonly used method of condition monitoring for bridges in the UK (e.g. McRobbie et al. (2015), Bennetts et al. (2016)) and can be considered to be a form of 'damage detection' structural health monitoring (SHM) according to Webb et al. (2015). Vardanega et al. (2016) developed a 'pre-monitoring value assessment matrix' which requires input from the 'SHM engineer', 'structural engineer' and 'owner/asset manager' and suggested that an assessment is required of how likely it is that the data collected will inform maintenance interventions.

Studies have raised concerns regarding the reliability of visual inspection data due to human factors (See et al., 2017), with several highlighting variability in the results of visual inspection of bridges due to inconsistencies in the recording of defects between individual inspectors (Graybeal et al., 2002; Lea and Middleton, 2002; Middleton, 2004; Moore et al., 2001). However, in a forthcoming paper, Bennetts et al. (2018) show that the aggregation of results to generate the derived metrics used in this work reduces the extent to which they are affected by variations in the underlying data; therefore, these metrics can be used to inform decision-making at a strategic level.

\section{Asset data held by Highways England}

Highways England holds data on its structures assets, including bridges, on the Structures Management Information System (SMIS) database. SMIS comprises a relational database and is structured with database tables containing static inventory information and a time history for events in a structure's life cycle, such as inspections, 
recording of new defects and subsequent treatment of those defects with maintenance actions. The system also includes a simple file server for documents related to each structure. Due to the complications of the event-based database topography and challenges in securely accessing the live database, the data for this work were requested as a set of static tables of data in comma-separated value (.csv) format. These were produced from the SMIS database by Highways England's information technology (IT) service providers by using scripts written in Structured Query Language. The specific data sets requested for this work, and provided by Highways England's IT service provider, are set out in the following subsections.

\subsection{Inventory data}

Tables of inventory data were provided covering the full inventory of bridges and large culverts on the network. These data included the full schedule of components that comprise each bridge and information such as the bridge type, maintaining agent, location and construction year. Due to differences in the level of data held on the SMIS database for structures managed as part of design, build, finance and operate (DBFO) arrangements, DBFO-managed structures were not included in this study. It was also necessary to remove a small number of structures from the study due to errors such as typos or missing fields in their data. In total, data from 7173 of the 8607 bridge records received were included in this study.

\subsection{Current condition data}

Bridge condition indicator (BCI) scores and element condition indicator (ECI) scores for each of the Highways England-owned structures (i.e. not including structures managed by DBFO concessionaires) on the network were provided. The IT service provider generated scores for each structure at yearly intervals from 1 April 2006 through 1 April 2016. Additional outputs of condition scores were also provided during the project on 1 November and 1 December 2016. Since the defect recording detail level in SMIS changed during this time, the scores from year to year are not necessarily directly comparable.

\subsection{Defect data}

Raw defect data were provided in the format of defect types, severities and extents, as recorded during biennial general inspections (GIs) and six-yearly principal inspections (PIs). These comprised approximately 500000 'current' defects, which are yet to be addressed by maintenance actions, and around 3000000 historic defect records which have been addressed. Bennetts et al. (2018) have demonstrated that, for Highways England's defect data, there is significant uncertainty in the allocation of individual defect scores due to variation between inspectors' opinions during visual inspection. However, these variations become much less significant when considering derived statistics, such as BCI scores, for large collections of structures.

\section{Analysis tools and methods}

3.1 Data analysis environment

A suite of scripts was developed to analyse the project's quantitative data and present results in the form of statistics and plots. These tools were used to calculate element, bridge and stock-level condition scores from the raw inventory and defect data and to evaluate changes over time. More complex tools were also developed to identify multifactor trends by adopting the machine learning algorithms used to build optimal decision trees to build importance dendrograms. The majority of these tools were developed in Python 3.x, making use of features from the Python toolkits scheduled in Appendix 2.

\subsection{Quantifying bridge condition}

Condition scores $\left(\mathrm{BCI}_{\mathrm{ave}}\right.$ and $\left.\mathrm{BCI}_{\text {crit }}\right)$, which are defined in detail in Appendix 1, have been calculated for each individual bridge according to the BCI system (Sterritt, 2002), with slight modifications to align with the SMIS recording format as set out by Bennetts et al. (2018) in their forthcoming paper.

\subsection{Analysis of the change in condition with time}

SMIS condition score reports were obtained for each year between 2006 and 2016, with the intention of allowing any changes in the condition of bridges and their components over time to be investigated. However, the recording of inspections was gradually migrated from the BE11 format to the current SMIS format between 2007 and 2016. Condition scores calculated using the two different inspection formats are not directly comparable, partly due to the increased level of detail recorded with the SMIS format defects are now recorded on individual components, such as individual bearings or beams, rather than groups of components. Therefore, it is not meaningful to plot the condition of the stock over time for the full 10 years of available data. However, there are some structures which have now had two PIs under the new inspection and recording regime, allowing comparisons to be made. There are not significant numbers of structures available for comparison until 2007; therefore, with the 6-year cycle of the PI programme, comparisons could be made only for four successive years. In each case, the first inspection was the year in which the structure was 'migrated' to the new SMIS inspection reporting format (Figure 1). For example, the cohort of structures labelled as 2007 was selected to consist of all the bridges which were migrated to the SMIS recording style in 2007 and had PIs in 2007 and 2013. Using the data available, it was possible to select three further cohorts of structures migrated to the new system in 2008, 2009 and 2010 and reinspected in 2014, 2015 and 2016, respectively.

Comparison of condition between two PIs was possible for a total of 2379 bridges; the breakdown by year is presented in Table 1. Comparisons of the condition of individual elements between inspections were possible for these structures, with a total of 25472 element conditions compared.

The conditions of these populations of bridges are plotted as the average $\mathrm{BCI}_{\text {crit }}$ and $\mathrm{BCI}_{\mathrm{ave}}$ scores for the population, weighted by deck area in Figure 1. Each marker has been coloured to indicate the pairwise comparison to which it relates, labelled by the first inspection in the comparison. Considering that the 2007 cohort is a smaller group of structures and appears to have performed worse 


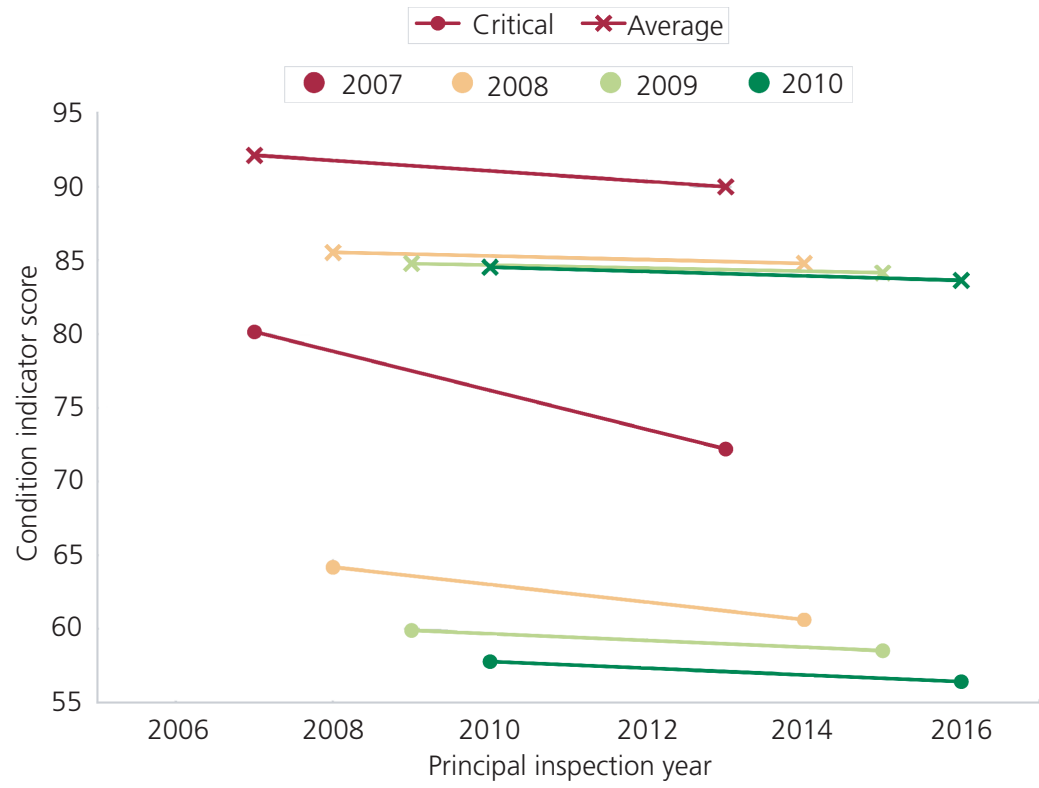

Figure 1. Change in condition between successive inspections for populations of structures that were inspected in the same year. The conditions of these populations of bridges are plotted as the average $\mathrm{BCl}_{\text {crit }}$ and $\mathrm{BCl}_{\text {ave }}$ scores for the population, weighted by deck area. A total of 2397 bridges are included in this plot

Table 1. Summary of the number of bridges and components included in each comparison cohort

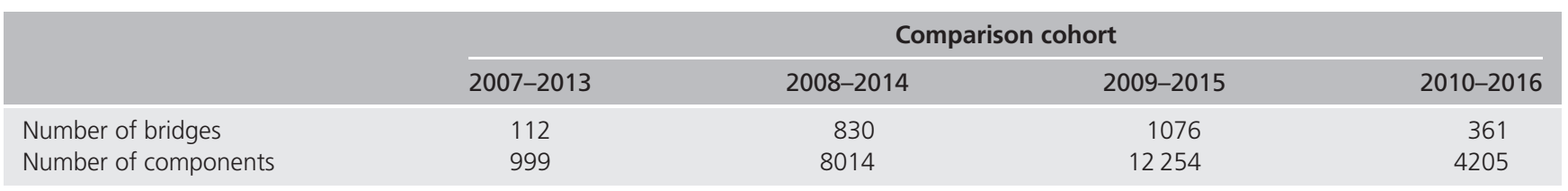

Data provided by Highways England

than the later cohorts of bridges, it appears likely that these results could be unrepresentative of the general trend, possibly due to some bias in the structures that were chosen for migration in the first year.

\subsection{Deterioration rates}

In addition to analysing changes in the condition of the whole bridge stock, it was also possible to consider the changes in the condition of particular subpopulations of structures by characteristics such as 'structure type', 'construction material' or obstacles crossed. This allowed deterioration rates for different types of structures to be estimated. For each structure, the rate of change of the condition score (for both average and critical scores) was estimated from the difference in score between two successive PIs - that is, over a 6-year time interval. Within each subpopulation, the changes in average $\mathrm{BCI}_{\mathrm{ave}}$ and $\mathrm{BCI}_{\text {crit }}$ scores (weighted by deck area) were then calculated.

Figures 6 and 7 show some differences between the performances of the different cohorts of structures. There is a possibility that this may be an artefact of the dates on which structures in different areas were migrated from BE11 to SMIS. For this reason, data from each of the four cohorts of structures have been plotted as separate markers. The weighted average of the four years is plotted as a black bar. It is noted that while some data points from 2007 appear anomalous, no cause could be attributed to this, and they do not significantly affect the location of the average. The size of each marker has been scaled by the number of bridges that it represents, such that outliers that represent only a small number of bridges can be readily identified.

\subsection{Use of importance dendrograms to identify multifactor trends}

Given the categorical nature and large number of attributes that can affect the performance of bridge structures, the heterogeneous nature of the UK's bridge stock and the potential for multifactor associations, it is not clear from standard data analysis techniques, such as simple linear regression, what the most influential variables are and whether there are particularly informative trends associated with specific subpopulations of bridges. For example, it would be difficult to identify in a structured way if there were a particular issue with the performance of a given type and age of bridge in a specific region of the network. To provide this structured methodology for identification of the most informative multifactor trends, an optimal decision tree machine learning method has been adopted as a form of data mining to derive hierarchical trees representing the most 
Smart Infrastructure and Construction

Volume 171 Issue SMIC1
Using data to explore trends in bridge

performance

Bennetts, Webb, Vardanega, Denton and Loudon influential factors affecting current bridge condition and the rate of change of condition. These trees have been rendered as 'importance dendrograms', graphically displaying the trends in bridge condition and rate of change in condition by categorical factors such as 'construction type' or 'region' for Highways England's stock of bridges.

\subsubsection{The optimal decision tree algorithm}

Decision trees can be considered to present a hierarchical series of questions about an object's attributes with the goal of gaining information about the object's likely value of a target attribute. They allow identification and presentation of the most influential categorical factors that affect the outcome of a target attribute. An optimal decision tree would partition the data set into values of the target variable as well as possible, with the smallest number of questions. The building of optimal decision trees allows categorical data sets to be processed and visualised, either for data mining (presented in this paper as importance dendrograms) or as a machine learning technique to allow predictions based on a training set of data. Optimal decision trees can be built in a top-down inductive manner, at each tier selecting the 'best' attribute to partition the data by. The choice of test for selecting the best attribute is important in developing a tool that will produce simple trees to classify data. Many tests have been proposed, such as statistical significance testing (Kass, 1980) or information gain (Quinlan, 1986). This work uses the information gain calculated in the same manner as the Iterative Dichotomiser 3 machine learning algorithm as described by Quinlan (1986), which uses the concept of information entropy (Shannon, 1948). The technique finds the entropy (a measure of the randomness, or uncertainty) of the whole data set and then finds the entropy of subsets of the data partitioned by the values of the attributes, weighted by their empirical probability. In this way, the information gained by partitioning on a certain attribute can be measured. The algorithm selects the attribute that results in the greatest information gain and then calls the process recursively on each of the subtrees created.

The concept of information entropy was first reported by Shannon (1948) as a method for characterising the uncertainty in a piece of information. Shannon (1948) proposed the use of logarithms because their properties matched the three key properties that he identified as fundamental to his concept. For a set of outcomes $n$ from an event each with probabilities $P_{1}, P_{2}, \ldots, P_{n}$, respectively, Shannon (1948: p. 10) suggested that a measure of the uncertainty in the outcome, $H\left(P_{1}, P_{2}, \ldots, P_{n}\right)$, would have the following properties.

1. $H$ should be continuous in the $P_{i}$.

2. If all the $P_{i}$ are equal, $P_{i}=1 / n$, then $H$ should be a monotonic increasing function of $n$. With equally likely events there is more choice, or uncertainty, when there are more possible events.

3. If a choice be broken down into two successive choices, the original $H$ should be the weighted sum of the individual values of $H$.
Shannon (1948: p. 11) explains that a function that satisfies these criteria has the following format

$$
\text { 1. } H=-K \sum_{i=1}^{n} P_{i} \log P_{i}
$$

Noting that if base 2 is used, the information gain is expressed in logical bits and that the constant $K$ serves only to scale the results; the following expression was proposed (Shannon, 1948)

$$
\text { 2. } H=-\sum_{i=1}^{n} P_{i} \log _{2} P_{i}
$$

Taking this measure of 'information gain', the categorical attributes of bridges, such as their structural form, articulation or construction material could be compared such that the attribute that provided the most information regarding the target attribute (in this case bridge condition or rate of deterioration) could be identified. This was then repeated for subsets of the data for each value of the chosen attribute - that is, if, for example, 'region' was the attribute that provided the most information, then the data were split into a subtree for each individual region and then the process was applied again for the remaining attributes.

Software tools implementing this process for bridge condition data were developed for this work in the Python 3.x environment to build optimised decision trees from input spreadsheets containing rows of items (in this example bridges), with columns giving the values of different attributes, the last of which being the target attribute. The Newick tree data structure, implemented in the Environment for Tree Exploration (ETE) 3 library (HuertaCepas et al., 2010), was used to store, traverse and render the resulting hierarchical data structure. The resulting hierarchical tree data structures were rendered as importance dendrograms with pie charts on the nodes to display the distribution of the target attribute (e.g. condition or change in condition) for the subtree below each node. The pie charts were drawn such that the area is inversely proportional to the entropy of the subtree; this allows the most informative results to be identified readily by the size of the pie chart. The depth of the trees has been limited, and only nodes representing a minimum number of structures have been drawn to improve the readability of the plots. Importance dendrograms have been generated and presented for the factors affecting the current condition of Highways England's bridge stock and for the rate of change in condition of the bridge stock.

\subsubsection{Details of parameters used to derive the importance dendrogram for condition}

To generate the importance dendrogram for current condition (Figure 5), the following attributes were given to the algorithm from which it selected the optimum tree topology: 'structure type', 'construction type', 'deck type', 'structure use', 'distance from coast', 'region' and 'age group'. 'Age group' splits the bridges into five bands from youngest to oldest with the same 
number of bridges in each band. 'Region' splits the bridges into the 14 'maintenance areas' into which the network is divided for the purposes of letting contracts for the maintenance and inspection of portions of the network. The names of the maintenance areas have been anonymised. Nodes, and their corresponding branches, have been drawn only if they represent at least 35 bridges. The depth of the dendrogram was limited to three partitions.

\subsubsection{Details of parameters used to derive the importance dendrogram for change in condition}

The following attributes were given to the algorithm from which it selected the optimum tree topology for change in bridge condition (Figure 10): 'structure type', 'construction type', 'deck type', 'structure use', 'distance from coast', 'region', 'age group',
$\mathrm{BCI}_{\mathrm{ave}}$ and comparison year. Where $\mathrm{BCI}_{\mathrm{ave}}$ splits the bridges into five bands by their $\mathrm{BCI}_{\text {ave }}$ condition score, from 'best' to 'worst'. The comparison year is the inspection year in which the first of the two compared sequential PIs took place.

\section{Results: trends in bridge condition}

The overall condition of Highways England's stock ( $n=7173$, excluding structures managed by DBFO contractors or those with records containing errors) is presented in Table 2. Overall, the vast majority of the bridge stock was found to be in either 'very good' or 'good' condition.

Figures 2 and 3 show the condition of Highways England's bridge stock, grouped by 'structure type' and 'deck type'. Figure 4 presents the current condition $\left(\mathrm{ECI}_{\mathrm{ave}}\right)$ of elements on

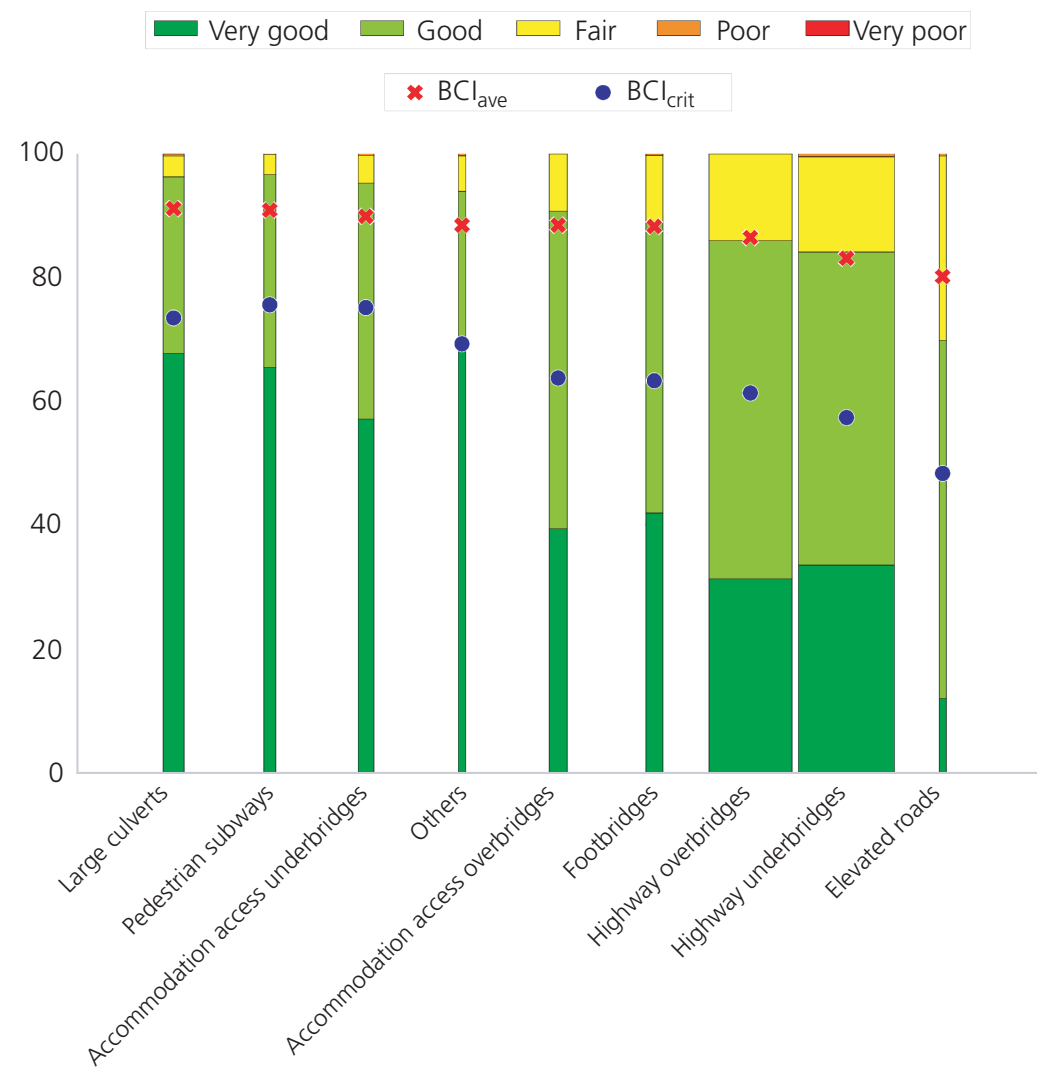

Figure 2. Bridge condition split by 'structure type' showing the distribution of average $\mathrm{BCl}$ scores $\left(\mathrm{BCl}_{\mathrm{ave}}\right)$ within each category of 'structure type' as percentages falling into the brackets of very poor, poor, fair, good and very good. Also shown are the average $\mathrm{BCl}_{\mathrm{ave}}$ and $\mathrm{BCl}_{\text {crit }}$ scores for the bridges in each category, which have been weighted by the deck area of each bridge. These scores are on a scale from 0 to 100 . The width of the bars has been scaled by the number of bridges in each category

Table 2. Stock level condition scores for all bridges on Highways England's network as at February 2017

\begin{tabular}{lccccccc}
\multirow{2}{*}{ Count } & $\mathbf{B C l}_{\text {ave }}$ & $\mathbf{B C l}_{\text {crit }}$ & \multicolumn{5}{c}{ Condition bandings (as defined in Appendix 1, Table 3): \% } \\
\cline { 4 - 8 } & & Very good & Good & Fair & Poor & Very poor \\
\hline 7173 & 84.1 & 58.2 & 39.50 & 47.80 & 12.30 & 0.40 & 0.00
\end{tabular}




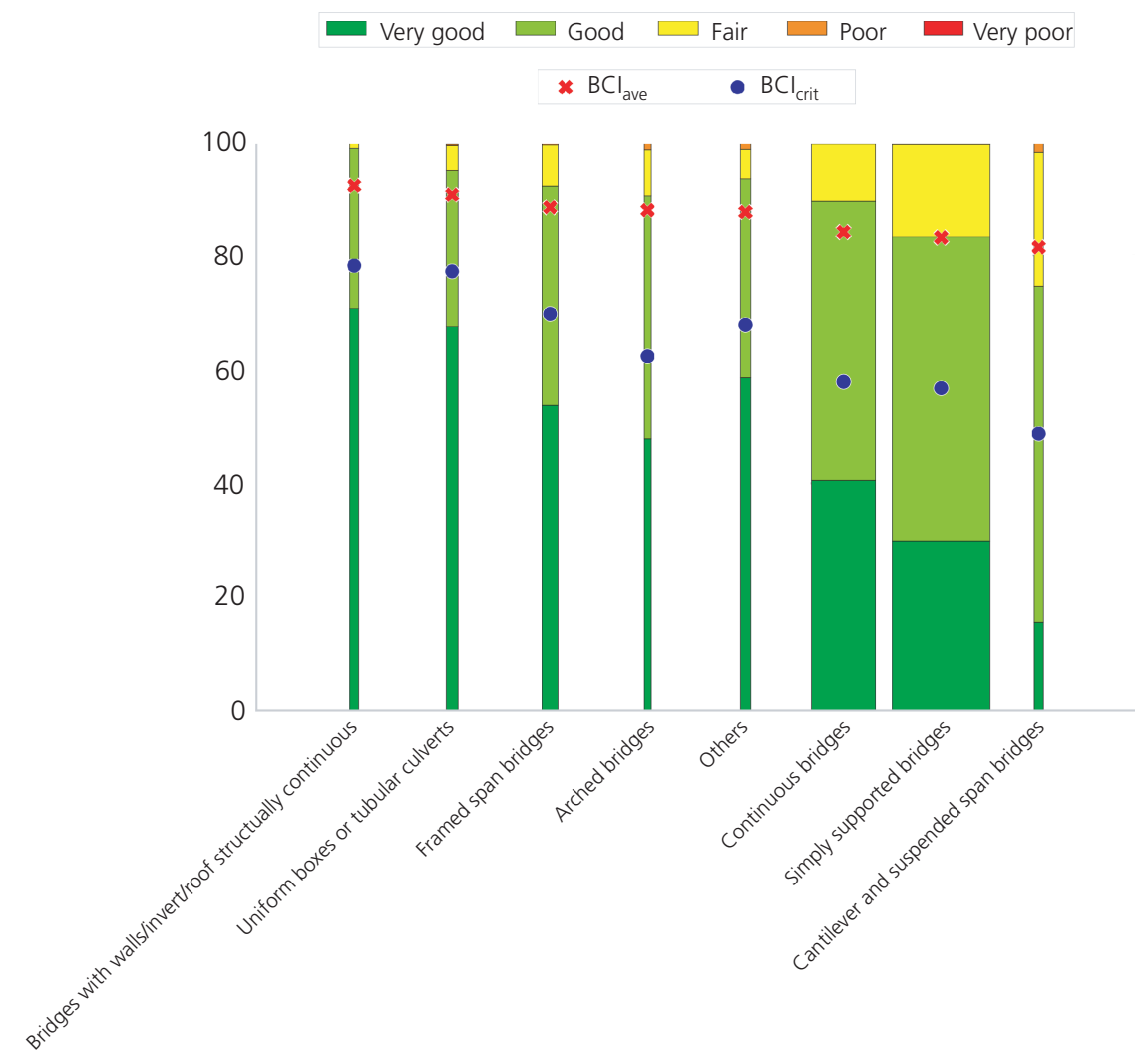

Figure 3. Bridge condition split by 'deck type' showing the distribution of average $\mathrm{BCl}$ scores $\left(\mathrm{BCl}_{\text {ave }}\right)$ within each category of 'deck type' as percentages falling into the brackets of very poor, poor, fair, good and very good. Also shown are the average $\mathrm{BCl}_{\text {ave }}$ and $\mathrm{BCl}_{\text {crit }} \mathrm{Scores}$ for the bridges in each category, which have been weighted by the deck area of each bridge. These scores are on a scale from 0 to 100. The width of the bars has been scaled by the number of bridges in each category

the network, split by component type. Figure 5 demonstrates that of the factors considered, structure age has the biggest effect on the condition of a bridge, followed in most cases by 'structure type' and 'deck type'. This is discussed further in Section 6.

\section{Results: trends in change in bridge condition}

Figure 1 shows that the condition of Highways England's stock on the whole is relatively static, with a slow rate of deterioration over the study period. Figures 6-9 show how the rate of change of condition varies as a function of bridge age and type.

Figure 10 shows that the most informative factor in the rate of change of condition is a structure's current condition. Counterintuitively, structures in better condition have deteriorated faster, while those in a poorer condition appear to have deteriorated more slowly. The maintenance 'region' and the 'structure type' are also influential in the rate of deterioration.

\section{Discussion}

\subsection{Factors affecting performance}

The majority of Highways England's bridge stock was found to be in good or very good condition when rated using the average
BCI score $\left(\mathrm{BCI}_{\mathrm{ave}}\right)$ (Table 2), with a slow rate of deterioration over the study period (Figure 1).

Figure 2 shows that, typically, elevated road structures are in the poorest condition. It can also be seen in Figure 8 that the rate of deterioration in average condition score $\left(\mathrm{BCI}_{\mathrm{ave}}\right)$ is fastest for elevated roads. However, the same trend does not appear to be repeated with the critical condition score $\left(\mathrm{BCI}_{\text {crit }}\right)$. Instead, Figure 9 shows that the average rate of change of $\mathrm{BCI}_{\text {crit }}$ for elevated roads is actually positive. This is possibly due to a relatively large number of maintenance interventions having been undertaken to rectify critical defects on elevated road structures during the study period. Large culverts are currently the structure type in the best condition; however, they demonstrated some of the fastest rates of deterioration in both the $\mathrm{BCI}_{\mathrm{ave}}$ and $\mathrm{BCI}_{\text {crit }}$ scores.

The current condition of overbridges can be seen to be better than that of underbridges (Figure 2). Additionally, underbridges can be seen to be deteriorating faster than overbridges (Figure 8). This appears to suggest that overbridges are generally more durable than underbridges. Considering that the decks of Highways England's underbridges carry the heavily gritted Strategic Road Network, it is possible that this poorer performance of underbridges is related to their higher exposure to chloride-based 


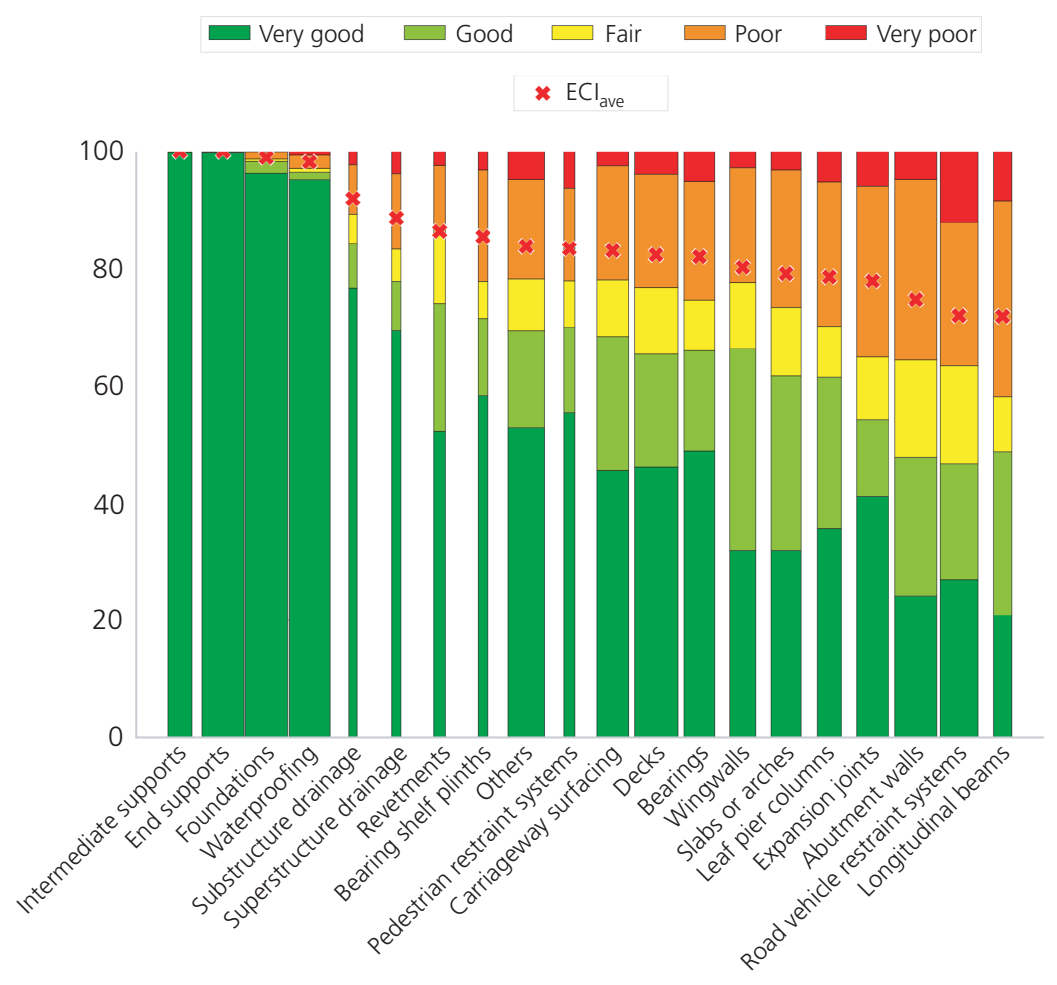

Figure 4. Element condition split by element type showing the distribution of average $\mathrm{ECI}$ scores $\left(\mathrm{ECl}_{\text {ave }}\right)$ within each category of element type as percentages falling into the brackets of very poor, poor, fair, good and very good. Also shown is the average of the ECI scores for each element type. These scores are on a scale from 0 to 100. The width of the bars has been scaled by the number of elements in each category, such that categories that represent only a small number of elements can be readily identified

de-icing salts (carried by water leakage through defective deck waterproofing, drainage or joints), which is known to accelerate the deterioration of concrete structures (e.g. Vassie (1984), Wallbank (1989), Bamforth et al. (1997), Abosrra (2010)).

In Figure 3, it can be seen that continuous structural forms tended to be in better condition than structures which are simply supported. However, the calculated deterioration rates show that simply supported structures appeared to deteriorate more slowly than continuous structures. One of the findings of Wallbank (1989) was that deck expansion joints were often found to leak, leading to an increased likelihood of chloride contaminated water reaching bridge substructures, with a consequential increase in the risk of deterioration. Wallbank (1989) proposed that continuous structures should be adopted where possible to reduce this risk. However, the evidence presented here does not seem to suggest that continuous structures are significantly more durable than those which are non-continuous.

Figure 5 shows that the most important factor affecting the average condition score of a structure was its age, with older structures typically having lower condition scores than newer structures. Figures 6 and 7 identify a decrease in the rate of deterioration of condition scores with increasing structure age. This implies that, typically, the condition of structures initially deteriorates rapidly before gradually levelling off, providing a deterioration curve very different from that presented in standard reference texts (e.g. Ryall (2010: p. 527)) and those normally assumed for asset management purposes in the UK (Atkins, 2015). The results correspond well to studies undertaken using data for bridges in Illinois (Bolukbasi et al., 2004) and Florida (Sobanjo, 2011), which show an initial higher rate of deterioration when structures are in a perfect condition, followed by a slower decline once structures are in a reasonable, but not excellent, condition. It is important to note that these data include the effects of both deterioration and maintenance interventions as it is not possible to remove the effects of maintenance from the condition data collected by inspectors. As a consequence of the inclusion of maintenance and renewals in these data, the lower end of the condition-time deterioration profile is likely to have been masked as interventions would have been made before structures' conditions fell to an unacceptable level (Highways Agency, 2014).

After 'structure age', 'deck type' and 'structure type' were also found to be highly influential factors on the average condition score of a structure. Detailed insights can be drawn from the decision trees results - for example, the conditions of simply supported highway overbridges and cantilever and suspended span structures in area E and simply supported elevated roads in area $\mathrm{J}$ were found to be particularly poor and were shown to be almost certain to be in below average condition. 


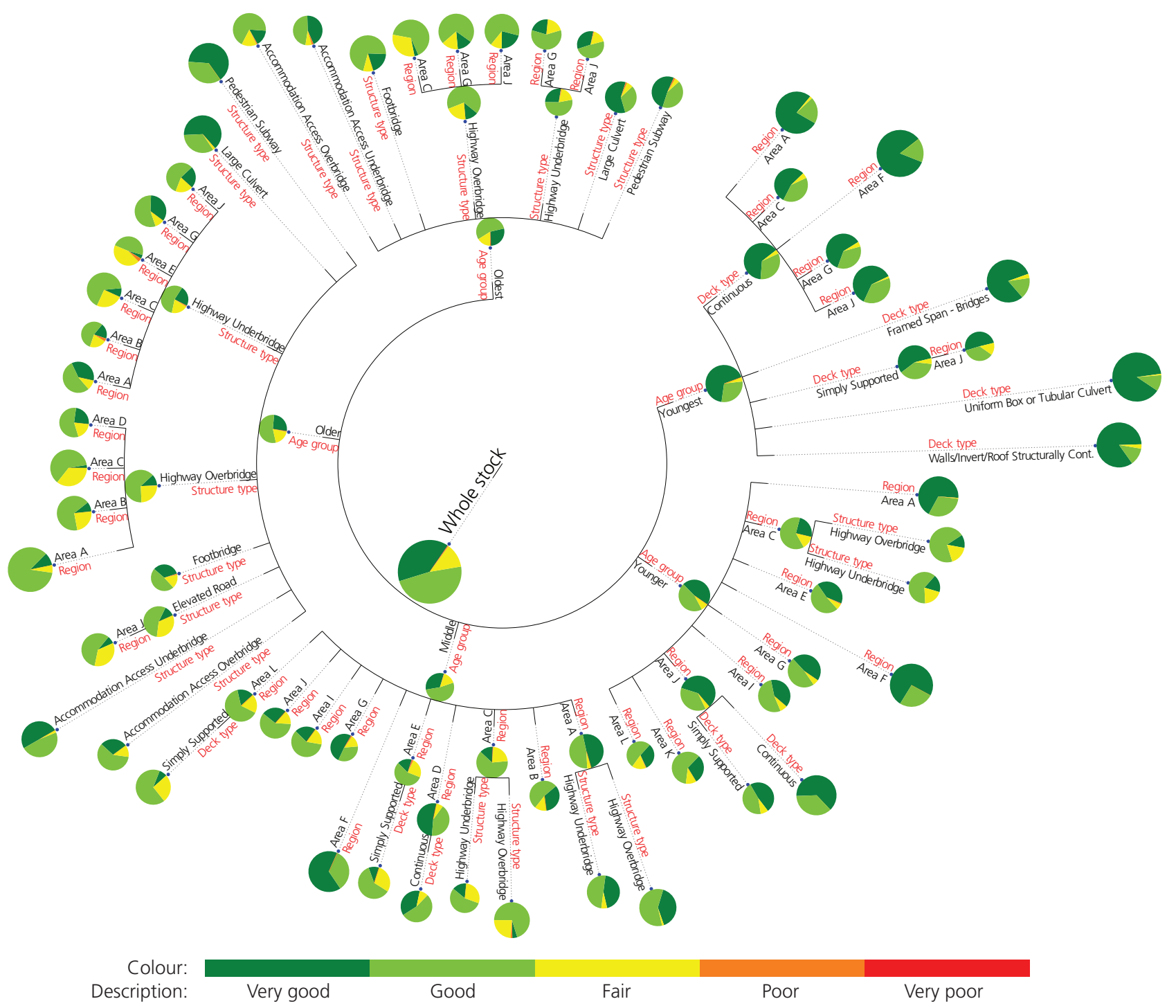

Figure 5. Importance dendrogram showing the most informative multifactor trends in average condition score ( $\left.\mathrm{BCl}_{\text {ave }}\right)$. The condition of the bridges has been banded from very good to very poor. Each pie chart represents the distribution of the condition bandings within the subpopulation below that point in the tree structure. The top 'Whole stock' pie chart represents the distribution of condition in the whole stock. The red text on each branch of the tree represents the attribute that the data set has been partitioned by at that level, and the black text represents the value of the attribute. The size of each node (pie chart) has been drawn inversely proportional to its entropy, such that the most informative partitions can be readily identified

The importance dendrogram plot in Figure 5 highlights that current condition and maintenance region were found to be the most influential factors affecting the rate of change of condition over time. Typically, structures reported to be in the best condition also had the highest deterioration rates, again implying that the condition of structures appears to deteriorate rapidly at first before levelling off later in their service life.

\subsection{Performance of components}

Primary structural components, such as longitudinal and transverse beams, were generally reported to be in worse condition than other components (Figure 4) and were also seen to exhibit some of the highest deterioration rates (Figure 11). Figure 4 shows that expansion joints were typically in poor condition, and in Figure 11, they also had a high rate of deterioration. This corroborates the finding of Wallbank (1989) that leaking expansion joints were frequently a cause for concern. From the results of this study, it appears that this is still the case. Drainage components were reported to be in fairly good condition, but with deterioration rates higher than most other components. Intermediate and end supports were reported to be in good condition and improving over time, suggesting recent investment in maintenance to improve their condition. 


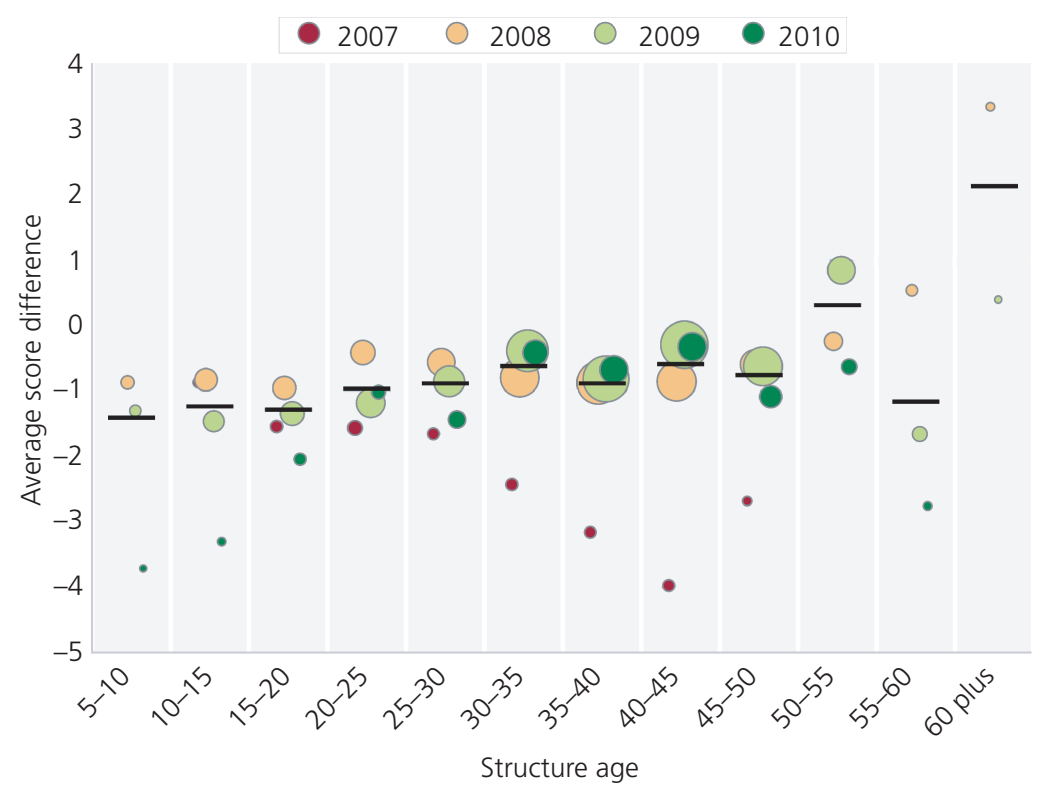

Figure 6. Deterioration rate plots showing the change in $\mathrm{BCl}_{\text {ave }}$ between successive inspections for populations of structures that were inspected in the same year, split by structure age. The change of condition with time of these populations of bridges has been plotted as the difference between the average $\mathrm{BCl}$ scores for the population in each of the successive inspections, weighted by deck area to account for the relative importance of larger structures. The markers have been shaded to indicate the comparison year. The size of the marker has been scaled by the number of bridges that it represents. The weighted average of the plotted comparison years has been plotted on the top as a black bar. Data from 2397 bridges are included in this plot

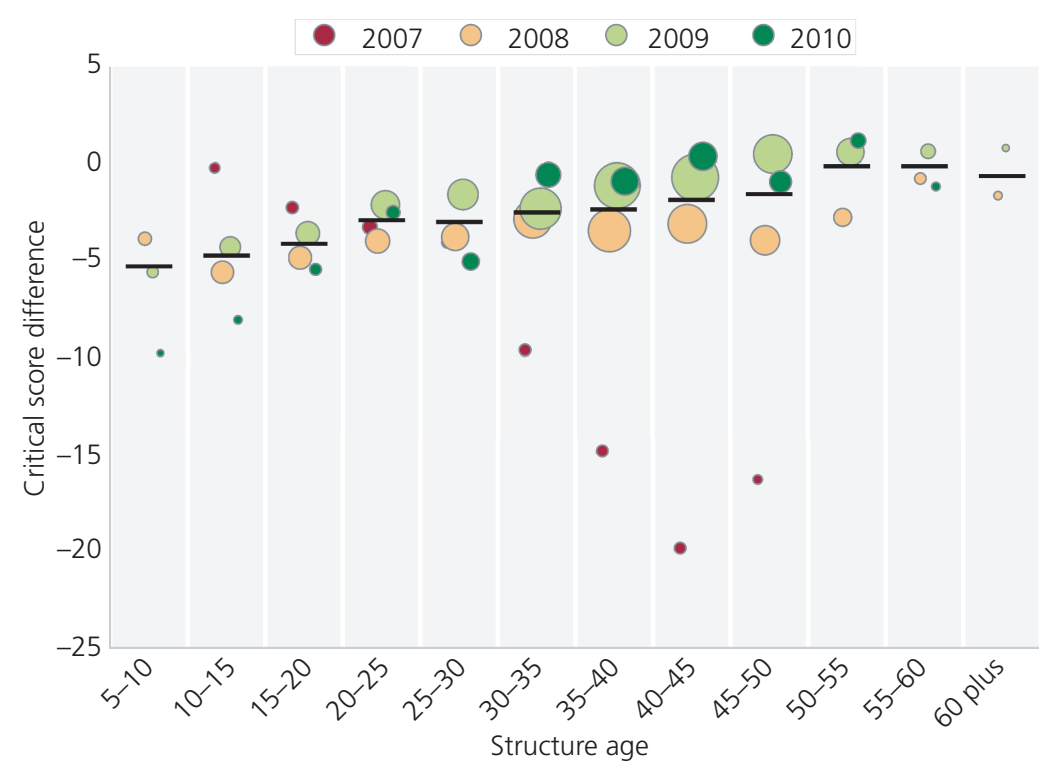

Figure 7. Deterioration rate plots showing the change in $\mathrm{BCI}_{\text {crit }}$ between successive inspections for populations of structures that were inspected in the same year, split by structure age. The change of condition with time of these populations of bridges has been plotted as the difference between the average $\mathrm{BCI}$ scores for the population in each of the successive inspections, weighted by deck area to account for the relative importance of larger structures. The markers have been shaded to indicate the comparison year. The size of the marker has been scaled by the number of bridges that it represents. The weighted average of the plotted comparison years has been plotted on the top as a black bar. Data from 2397 bridges are included in this plot 


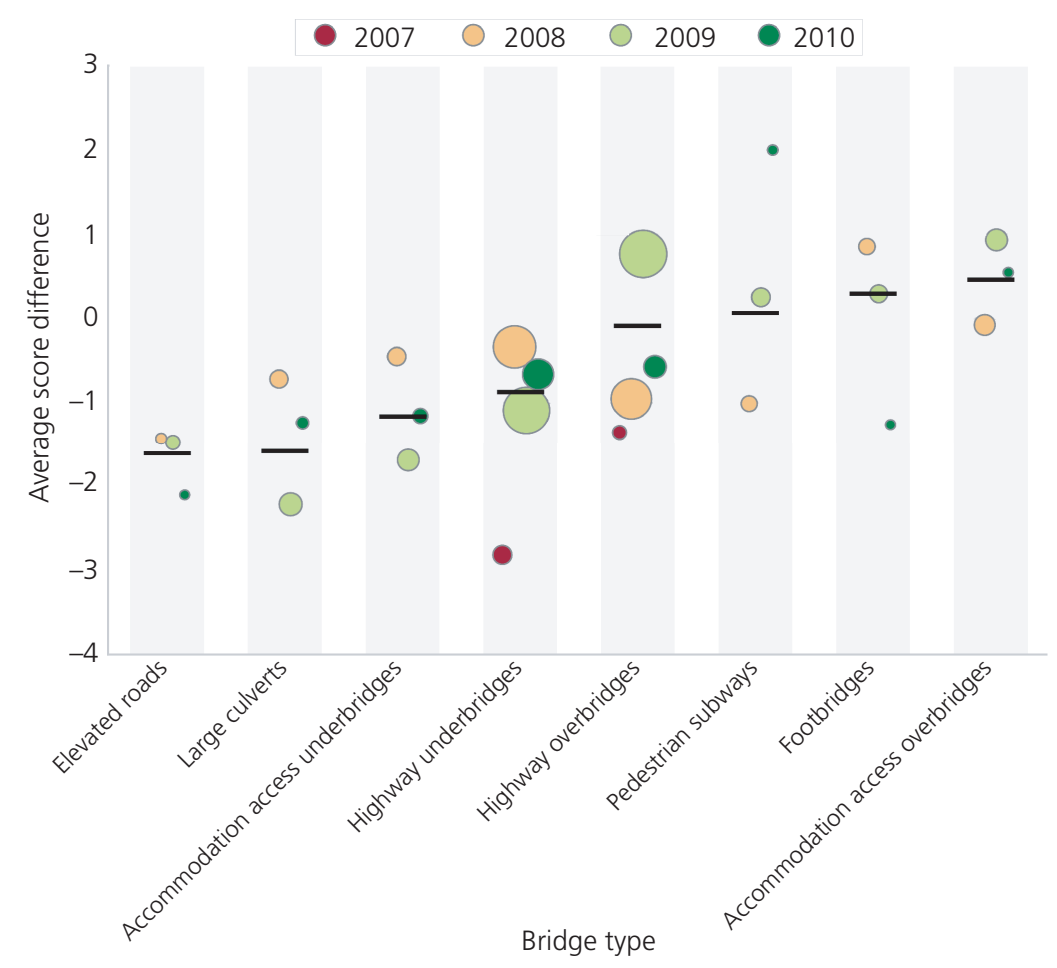

Figure 8. Deterioration rate plots showing the change in $\mathrm{BCl}_{\text {ave }}$ between successive inspections for populations of structures that were inspected in the same year, split by bridge type. The change of condition with time of these populations of bridges has been plotted as the difference between the average $\mathrm{BCl}$ scores for the population in each of the successive inspections, weighted by deck area to account for the relative importance of larger structures. The markers have been shaded to indicate the comparison year. The size of the marker has been scaled by the number of bridges that it represents. The weighted average of the plotted comparison years has been plotted on the top as a black bar. Data from 2397 bridges are included in this plot

\subsection{Availability of data and opportunities for the future}

The data made available for this work comprised a large data set including detailed inventory information for all the bridges on England's motorway and trunk road network and the individual components which they comprise. The hierarchical component inventory was enhanced in 2007 to include a greater level of detail for example, including 'child' components such as 'pre-stressed concrete beams' under 'parent' components such as 'deck'. Recording of condition information from PIs was migrated to this new detail level on a bridge-by-bridge basis between 2007 and 2016. As condition scores calculated from defect data recorded at this higher level of detail are not comparable with those used previously, tracking and analysis of individual bridges' conditions over time was possible only from 2007 onwards and then only for a subset of the stock. The corollary of this is that 2016 marked the first practical point in time that this study could be undertaken, and that for rate of change in condition, this work was necessarily limited to comparing changes over only one full PI cycle (including two intermediate GIs) and for only a subset of the full stock of bridges.

Identifying trends in the condition of the stock was complicated by the lagging effect the 2-year/6-year GI/PI cycle has on recording of changes in condition. Further, as the rate of deterioration for many components is slow and the defect grading system is coarse, some components may stay recorded at the same condition for several inspection cycles. Without the full time history of condition for all the bridges on the network, it is difficult to determine how long an individual component has been at a given condition rating and therefore its rate of change if it has changed. Additional complexity is added by the variability between the opinions of inspectors from one inspection to the next. For rapidly deteriorating or short-lifetime elements, there is a risk that the inspection interval is too infrequent to detect defects reliably before components enter a dangerous state (Sheils et al., 2012). A relatively simple amendment to the specification for the data recorded to include categorisation of the rate of change since the previous inspection could assist in resolving these issues.

This study focuses on insights from condition data as recorded during visual inspections and notes that the relationship between condition and key performance characteristics such as capacity, safety and serviceability is complex.

With all bridges now migrated to the more detailed recording format and an ever-increasing number with more than one PI recorded in this new format, there is potential for analysis of these data to be used to inform decision-making. The historic condition data could be used to calibrate and update deterioration models and could begin to 


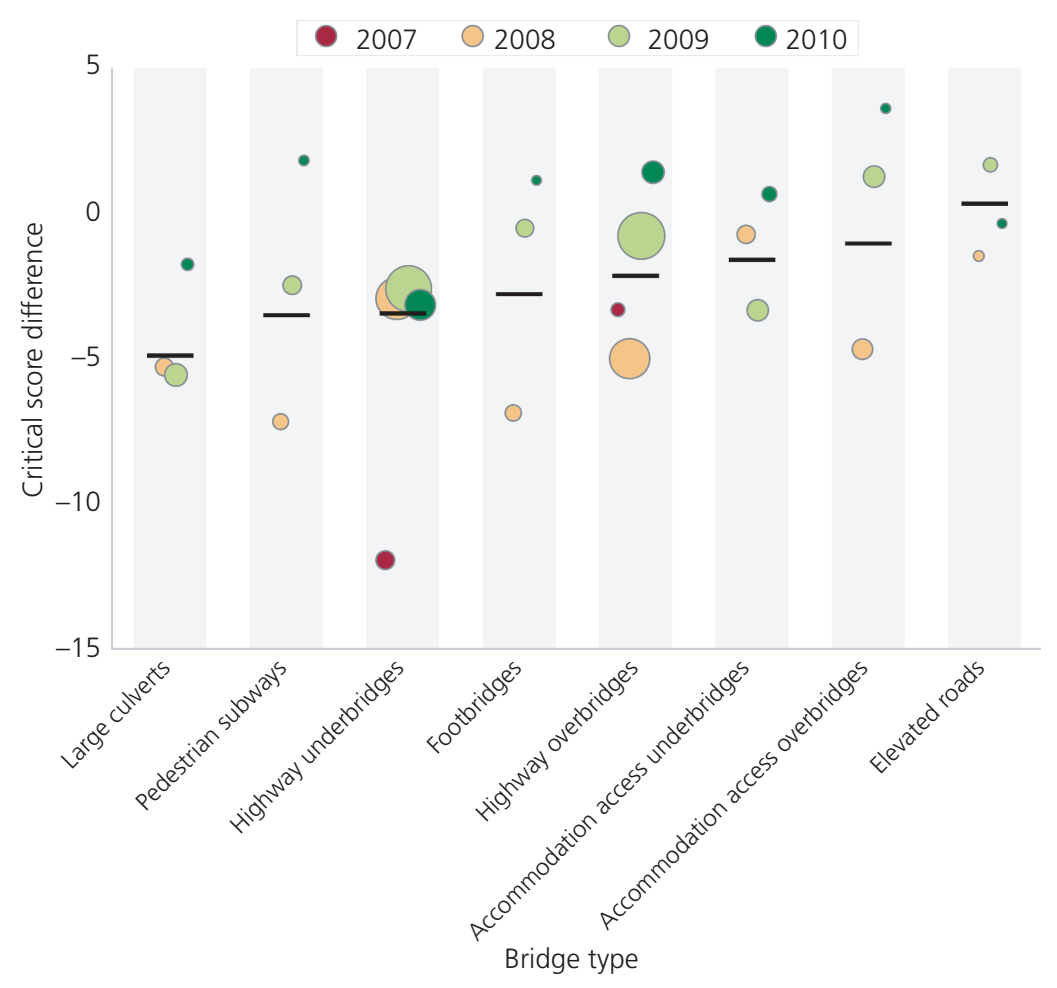

Figure 9. Deterioration rate plots showing the change in $\mathrm{BCl}_{\text {crit }}$ between successive inspections for populations of structures that were inspected in the same year, split by bridge type. The change of condition with time of these populations of bridges has been plotted as the difference between the average $\mathrm{BCl}$ scores for the population in each of the successive inspections, weighted by deck area to account for the relative importance of larger structures. The markers have been shaded to indicate the comparison year. The size of the marker has been scaled by the number of bridges that it represents. The weighted average of the plotted comparison years has been plotted on the top as a black bar. Data from 2397 bridges are included in this plot

fulfil the aspirations of an integrated bridge management system where data on past performance are used to influence decisionmaking for interventions (e.g. Woodward et al. (2001) - the Bridge Management in Europe project) which, while reported to be in other countries (e.g. Shepard (2005): USA), Mirzaei et al. (2012): global), are not widely adopted in the UK (Bennetts et al., 2016).

Asset condition data as used in this study require in-depth visual inspections to obtain, which can be costly and require disruption to the highway network; it is therefore important that the value of the data is recognised by bridge-owning organisations and that these are stored and managed accordingly. Furthermore, because the value of the data increases with the length of historic data available, it is crucial to avoid changes to the way in which data are collected that are not backwards compatible to ensure that data collected today can still be used in the future.

\section{Conclusions}

- A range of data analysis and presentation techniques have been demonstrated which can provide significant additional insight into existing data held about the current condition (and rate of change of condition) of Highways England's bridge stock. Optimal decision trees have been used to identify the most influential factors in the performance of structures and present these multifactor trends in a format readily digested by decision makers.

- 'Age', 'deck type' and 'structure type' were found to be the most influential factors affecting the average condition score $\left(\mathrm{BCI}_{\mathrm{ave}}\right)$.

- 'Structure condition' was found to be the most influential factor in the rate of deterioration, with structures in a better condition found to be deteriorating at a faster rate than those in a worse condition.

- Newer structures were also found to be deteriorating at a faster rate than older structures, suggesting that the condition of structures initially deteriorates rapidly before gradually levelling off.

\section{Acknowledgements and Data Availability Statement}

The authors thank Highways England and Lockheed Martin for use of portions of the SMIS database as part of this research project. No new experimental data were collected during this study. The authors would also like to thank Professor Colin Taylor and the Engineering and Physical Sciences Research Council Grant Number EP/G037353/1 (Industrial Doctorate Centre: Systems). The authors thank the anonymous reviewers for their helpful suggestions and comments. 


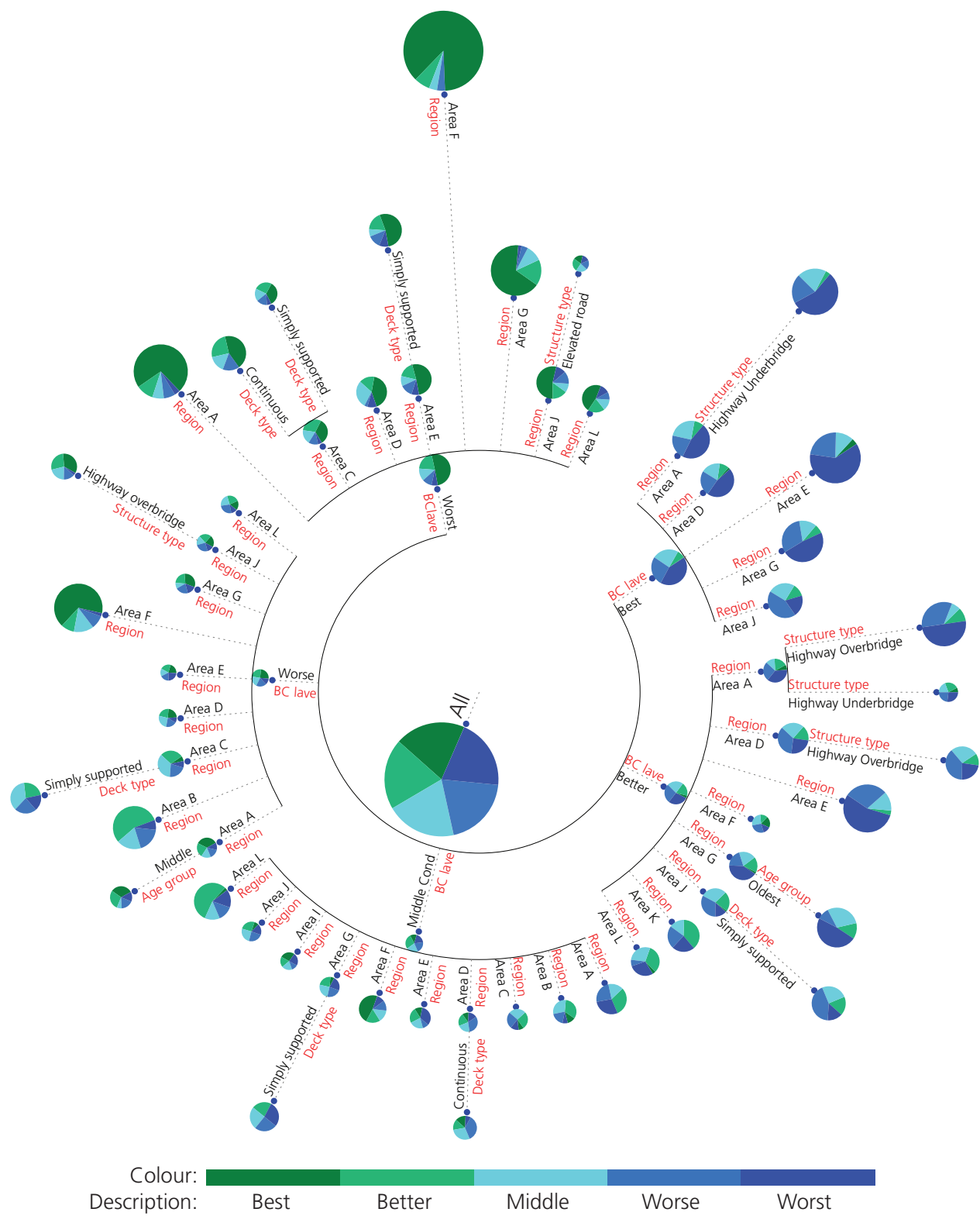

Figure 10. Importance dendrogram showing the most informative multifactor trends in change in average condition score ( $\left.\mathrm{BCl}_{\text {ave }}\right)$. The change in condition of the bridges between two consecutive Pls has been banded from best to worst by using an even split into five bandings with the same number of bridges in each. Each pie chart represents the distribution of the condition change bandings within the subpopulation below that point in the tree structure. The top 'All' pie chart represents the distribution of change in condition in the full population of bridges for which direct comparisons could be made. The red text on each branch of the tree represents the attribute that the data set has been partitioned by at that level, and the black text represents the value of the attribute 


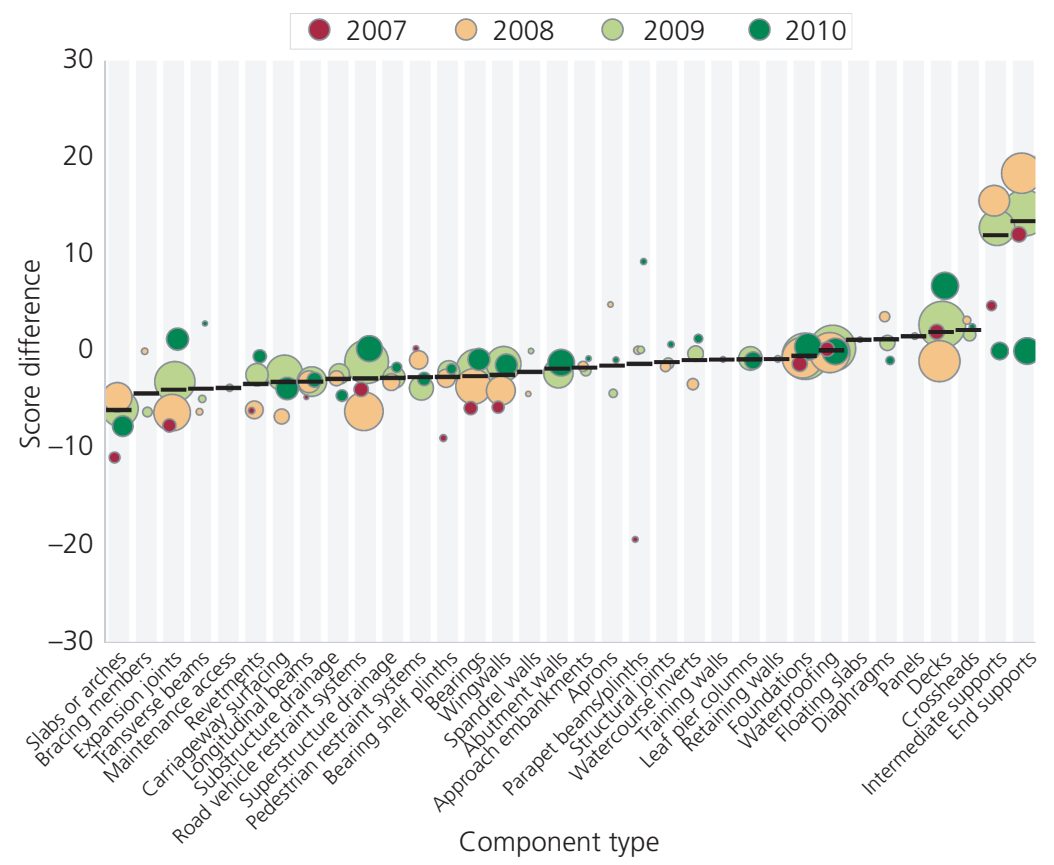

Figure 11. Change in condition between successive inspections for populations of components that were inspected in the same year. These $\mathrm{ECl}$ scores have been split by component type to show differences in the rate of deterioration. The change of condition with time of these populations of components has been plotted as the difference between the average $\mathrm{ECI}$ scores for the population in each of the successive inspections. The markers have been shaded to indicate the comparison year (by the first year of the pairwise comparison). The size of the marker has been scaled by the number of components that it represents, such that outliers that represent only a small number of bridges can be readily identified. Markers have been drawn only where they represent ten or more components. The weighted average of the plotted comparison years has been plotted on the top as a black bar

\section{Appendix 1}

The key terminology used in this paper is defined in this Appendix and in Table 4. BCI scores, $\mathrm{BCI}_{\mathrm{ave}}$ and $\mathrm{BCI}_{\text {crit }}$, are a measure of the condition of a structure on a scale from 0 to 100 , with 100 representing perfect condition. The average score, $\mathrm{BCI}_{\mathrm{ave}}$, is calculated from the raw defect scores, taking the worst defects on each component type, weighted by the structural importance of each element. The critical score represents the worst defect on the most important structural components. Further details on the calculation of these scores are presented by Sterritt (2002). For groups of more than one structure, the scores have been aggregated and reported and plotted as three metrics

- average bridge condition indicator for each subpopulation, weighted by the deck area of each individual structure

- critical bridge condition indicator for each subpopulation, weighted by the deck area of each individual structure
- average bridge condition indicator banding, which shows the distribution of condition within each subpopulation; the proportion of structures in each banding are shown as coloured bars, with the width of the bars representing the total number of structures in each subpopulation.

The scoring bands used are shown in Table 3.

Table 3. Condition bandings for $\mathrm{BCl}$

\begin{tabular}{|lc}
\hline Condition band & Condition performance indicator score \\
\hline Very good & $90-100$ \\
Good & $80-90$ \\
Fair & $65-80$ \\
Poor & $40-65$ \\
Very poor & $0-40$
\end{tabular}


Smart Infrastructure and Construction

Volume 171 Issue SMIC 1
Using data to explore trends in bridge

performance

Bennetts, Webb, Vardanega, Denton and Loudon
Table 4. Other terminology

\begin{tabular}{ll} 
Term & \multicolumn{1}{c}{ Definition } \\
Principal inspection & In-depth visual inspection conducted at \\
& six-yearly intervals; access, such as \\
& underbridge units or mobile elevated \\
& working platforms should be provided to \\
& ensure inspectors can access all areas of the \\
& structure to within touching distance \\
& (Highways Agency, 2007) \\
Reneral inspection & Routine visual inspection conducted at two- \\
& yearly intervals; no specialised access \\
Structure type & equipment is used (Highways Agency, 2007) \\
Description of the structure in terms of the \\
obstacles crossed and their relative positions \\
- for example, a 'highway overbridge' is a \\
bridge that carries a highway over a \\
Highways England motorway or trunk road; \\
primary construction material - for example, \\
'concrete' \\
Primary construction material - for example, \\
'concrete' and 'composite' \\
Structural form of a bridge, usually with \\
reference to the articulation - for example, \\
'simply supported' and 'cantilever and \\
suspended span' \\
Class of highway the structure is on: 'A' - \\
motorway class A road; 'M' - motorway; 'T' \\
- trunk road \\
The Highways England network is split \\
geographically into a series of 'areas', for \\
which contracts are let for services such as \\
maintenance, inspection and renewals; the \\
names of these areas have been anonymised \\
in this work to avoid attribution of results to \\
specific service providers \\
Deck type
\end{tabular}

\section{Appendix 2}

The following libraries were used with Python 3 for the processing and visualisation of data in this work

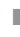

- SciPy 0.19 .0

- Pandas 0.19.1

- Matplotlib 1.5.3

- Basemap 1.0.8

- Seaborn 0.7.1

- Pyshp 1.2.10

- Python-dateutil 2.6.0

- ETE 3 (Huerta-Cepas et al., 2010).

\section{REFERENCES}

Abosrra LR (2010) Corrosion of Steel Reinforcement in Concrete. PhD thesis, University of Bradford, Bradford, UK.

Atkins (2015) Structures Asset Management Planning Toolkit Part A: Methodology. UK Bridges Board, UK.

Bamforth PB, Price WF and Emerson M (1997) An International Review of Chloride Ingress into Structural Concrete. TRL Ltd, Berkshire, UK, TRL Contractor Report 359.
Bennetts J, Vardanega PJ, Taylor CA and Denton SR (2016) Bridge data what do we collect and how do we use it? In Transforming the Future of Infrastructure through Smarter Information: Proceedings of the International Conference on Smart Infrastructure and Construction, 27-29 June 2016 (Mair RJ, Soga K, Jin Y, Parlikad AK and Schooling JM (eds)). ICE Publishing, London, UK, pp. 531-536.

Bennetts J, Webb G, Vardanega P, Denton S and Loudon N (2018) Quantifying uncertainty in visual inspection data. In Maintenance, Safety, Risk, Management and Life-Cycle Performance of Bridges (Powers N, Frangopol DM, Al-Mahaidi R and Caprani C (eds)). Taylor \& Francis, London, UK, pp. 2252-2259 (full-paper USB). Bolukbasi M, Mohammadi J and Arditi D (2004) Estimating the future condition of highway bridge components using national bridge Inventory data. Practice Periodical on Structural Design and Construction 9(1): 16-25, http://dx.doi.org/10.1061/(ASCE)1084-0680(2004)9:1(16).

Graybeal B, Phares B, Rolander D, Moore M and Washer G (2002) Visual inspection of highway bridges. Journal of Nondestructive Evaluation 21(3): 67-83, http://dx.doi.org/10.1023/A:1022508121821.

Highways Agency (2007) Inspection of highway structures. Design Manual for Roads and Bridges. Her Majesty's Stationery Office, London, UK, BD 63/07. See https://www.hrsservices.co.uk/wpcontent/uploads/2016/12/bd6307-Highways-Structures-IM.pdf (accessed 20/02/2018).

Highways Agency (2014) Network Delivery and Development Directorate NDD Portfolio Control Framework Handbook. Highways Agency, Guildford, UK. See http://assets.highways.gov.uk/specialistinformation/guidance-and-best-practice-forward-planning-guidance/ 2014-03-07_NDD_PCF_Handbook_v0.16.pdf (accessed 20/02/2018).

Highways England (2014) Highways England Strategic Business Plan 2015-2020. Highways England, London, UK. See https://www.gov. uk/government/uploads/system/uploads/attachment_data/file/396487/ 141209 Strategic Business Plan Final.pdf (accessed 20/02/2018).

Huerta-Cepas J, Dopazo J and Gabaldón T (2010) ETE: a python Environment for Tree Exploration. BMC Bioinformatics 11: 24, http:// dx.doi.org/10.1186/1471-2105-11-24.

Kass GV (1980) An exploratory technique for investigating large quantities of categorical data. Journal of the Royal Statistical Society. Series C (Applied Statistics) 29(2): 119-127, http://dx.doi.org/10.2307/2986296.

Lea F and Middleton C (2002) Reliability of Visual Inspection of Highway Bridges. Department of Engineering, University of Cambridge, Cambridge, UK, CUED/D-STRUCT/TR.201.

McRobbie SG, Wright MA and Chan A (2015) Can technology improve routine visual bridge inspections? Proceedings of the Institution of Civil Engineers - Bridge Engineering 168(3): 197-207, https://doi. org/10.1680/jbren.12.00022.

Middleton C (2004) Bridge management and assessment in the UK. Proceedings of the Austroads 2004 Bridge Conference: Bridges Another Dimension, Hobart, Australia. See http://bridgeforum.org/ files/pub/2004/austroads5/Middleton\%20keynote.pdf (accessed 20/05/ 2018).

Mirzaei Z, Adey BT, Leo K and Kong JS (2012) IABMAS Overview of Existing Bridge Management Systems 2012. International Association for Bridge Maintenance and Safety Bridge Management Committee 2012.

Moore M, Phares B, Graybeal B, Rolander D and Washer G (2001) Reliability of Visual Inspection for Highway Bridges. Federal Highway Administration, US Department of Transport, Washington DC, USA, vol. 1.

Quinlan J (1986) Induction of decision trees. Machine Learning 1(1): 81-106, http://dx.doi.org/10.1023/A:1022643204877.

Ryall MJ (2010) Bridge Management, 2nd edn. Butterworth-Heinemann Oxford, UK.

See JE, Drury CG, Speed A, Williams A and Khalandi N (2017) The role of visual inspection in the 21st century. Proceedings of the Human Factors and Ergonomics Society Annual Meeting 61(1): 262-266, https://doi.org/10.1177/1541931213601548. 
Smart Infrastructure and Construction

Volume 171 Issue SMIC1
Using data to explore trends in bridge

performance

Bennetts, Webb, Vardanega, Denton and Loudon
Shannon CE (1948) A Mathematical Theory of Communication (Reprinted with Corrections from the Bell System Technical Journal, Vol. 27, pp. 379-423, 623-656, July, October, 1948). See math.harvard.edu/ ctm/ home/text/others/shannon/entropy/entropy.pdf (accessed 11/06/2018).

Sheils E, O'Connor A, Schoefs F and Breysse D (2012) Investigation of the effect of the quality of inspection techniques on the optimal inspection interval for structures. Structure and Infrastructure Engineering 8(6): 557-568, http://dx.doi.org/10.1080/15732479.2010.505377.

Shepard RW (2005) Bridge management issues in a large agency. Structure and Infrastructure Engineering 1(2): 159-164, http://dx.doi. org/10.1080/15732470412331289378.

Sobanjo JO (2011) State transition probabilities in bridge deterioration based on Weibull sojourn times. Structure and Infrastructure Engineering 7(10): 747-764, http://dx.doi.org/10.1080/15732470902917028.

Sterritt G (2002) Bridge Condition Indicators. WS Atkins for CSS Bridges Group, London, UK, vol. 1.

UK Roads Liaison Group (2016) Well-managed Highway Infrastructure: a Code of Practice. Department for Transport, London, UK.
Vardanega PJ, Webb GT, Fidler PRA and Middleton CR (2016) Assessing the potential value of bridge monitoring systems. Proceedings of the Institution of Civil Engineers - Bridge Engineering 169(2): 126-138, https://doi.org/10.1680/jbren.15.00016.

Vassie P (1984) Reinforcement corrosion and the durability of concrete bridges. Proceedings of the Institution of Civil Engineers - Part 1 76(3): 713-723, https://doi.org/10.1680/iicep.1984.1207.

Wallbank EJ (1989) The Performance of Concrete Bridges: a Survey of 200 Highway Bridges. Her Majesty's Stationery Office, London, UK.

Webb GT, Vardanega PJ and Middleton CR (2015) Categories of SHM deployments: technologies and capabilities. Journal of Bridge Engineering 20(11): 04014118, http://dx.doi.org/10.1061/(ASCE)BE. 1943-5592.0000735.

Woodward RJ, Cullington WD, Daly FA et al. (2001) Bridge Management in Europe - Final Report. BRIME PL97-2220: Final Report/D14/ March 2001. See http://www.transport-research.info/sites/default/files/ project/documents/brimerep.pdf (accessed 20/02/2018).

\section{How can you contribute?}

To discuss this paper, please email up to 500 words to the editor at journals@ice.org.uk. Your contribution will be forwarded to the author(s) for a reply and, if considered appropriate by the editorial board, it will be published as discussion in a future issue of the journal.

Proceedings journals rely entirely on contributions from the civil engineering profession (and allied disciplines). Information about how to submit your paper online is available at www.icevirtuallibrary.com/page/authors, where you will also find detailed author guidelines. 